\title{
Research on the Practice Education in Colleges and Universities under the Background of Internet Plus
}

\author{
Li hongxin \\ Logistics Trade College, Xi'An Eurasia University , \\ Xi'An 710065 China
}

\begin{abstract}
In this paper, we conduct research on the practice education in colleges and the universities under the background of the Internet plus. The modern teaching method system is a system and its primary characteristic is systemically. In system composed of a variety of teaching methods, they all around a teaching goal, according to the characteristics of the teaching content, teaching object and teaching environment, each with their own teaching methods, the method, take part of the teaching task and various methods to connect with each other and interacting. If leave the system, then, they may no longer exists or has been greatly weakened. To enhance the traditional teaching methodology, we integrate the Internet perspective to form the novel types of the education pattern which will in some degree optimize the education flowcharts.
\end{abstract}

\section{Keywords- Practice Education, Colleges and Universities, Internet Plus, Background.}

\section{Introduction}

Internet thinking is to make full use of the spirit of the Internet, value, technology, methods, rules, the opportunity to guide, processing, and innovation of a thought, it contains the innovative thinking, cooperative, thinking, open thinking, systematic thinking aspects of content, is the inevitable outcome of the times development. The Internet thinking plays an important role in social development, has the superiority, leading in terms of the talent cultivation. In the current information age, the
Internet application of thinking to the teaching reform of colleges and universities as is also kind of inevitable trend. In recent years, China's colleges and universities teaching obtain great progress, the cultivation of talents in both thinking level and great changes have taken place both in practical level. However, with the rapid development of Internet technology, to train talents with Internet thinking become the primary task of the teaching in colleges and universities in our country [1-2].

Under this background, we summarize the corresponding teaching patterns as the follows. (1) The traditional teaching model. In the process of the traditional teaching, is the classic teaching mode is given priority to, teacher in the teacher speaks, students listen to, it is a kind of teaching mode of the one-way communication. Implementation on the Internet that the biggest advantage is that it breaks through the traditional teaching methods in the classroom the limitation of the number and location, the biggest drawback is the lack of the kind of the atmosphere in the face of the teacher in class, the authenticity of learning situation is not strong. (2) Assist the learning. The web-based collaborative learning refers to the use of computer network and multimedia related technologies, such as by many learners on the same learning content interaction and cooperation with each other, in order to achieve to the teaching content more profound understanding and grasp of the goal. (3) Guide the research. This learning mode thoroughly changed the traditional teaching of middle school students passively accept form, and make the students in active status, thus can effectively stimulate students' interest in the learning and creativity. (4) To explore the 
learning. This pattern is commonly monitored by the full-time teachers, namely by the experts and professional teachers in all areas of site to establish the corresponding subject matter discussion groups, students can study in our specific subject area, and able to comment on individual opinion, that everyone's speech comments can cover all learners see discussion in a timely manner which will enhance the property of cooperation [3-4].

The practice teaching practice exploration based on tacit knowledge based on the discussion of the knowledge and practice. Dewey think the process of practical experience and closely and necessary link between education, experience the continuity and the interaction of jointly promote the growth of the people. In terms of the relationship between curriculum and teaching,
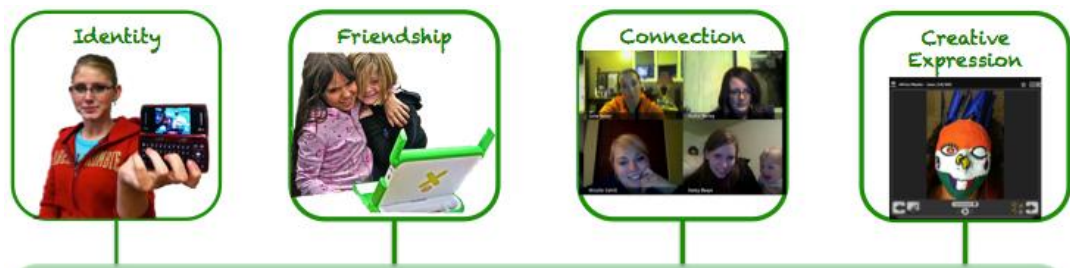

The Internet \& Social Networking for Enhancing Social-Emotional Learning
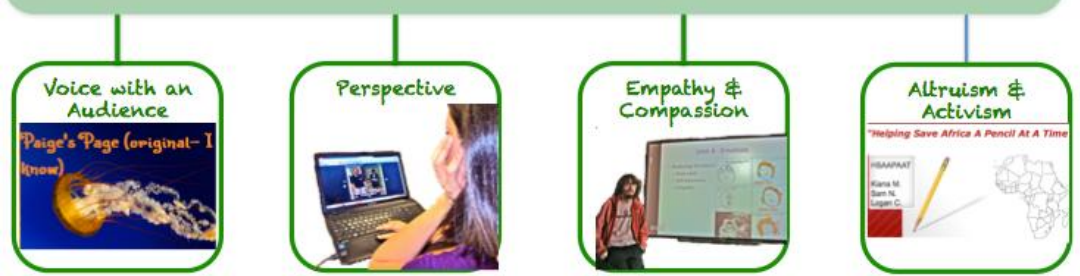

Figure 1. The Principles of Internet Plus and Practice Education Scenarios

In this paper, we conduct research on the practice education in colleges and universities under the background of Internet plus. University of the practice teaching and theories teaching is different, the former mentor is the status of teachers and students are the main body, mainly through the practice exploration, practice experience, promotes the innovation spirit and the practice ability, which makes, after-school activities become the significant spatial patterns. Compared in terms of theory teaching, practice teaching activity space is relatively complex, the purpose is more diverse that involved in the classroom, extracurricular, and multiple scene outside, involves the knowledge development, skills and ethics promoting multiple purposes, which determines the university practice teaching diversity, and between different types of scenarios and structural system and contact each other. In the following sections, we will talk about the corresponding theories in detail. 


\section{The Proposed Methodology}

The Education Reform and the Features. Institutions of higher learning is an important base of cultivating innovative talents, is an important part of national innovation system, in the construction of an innovative country has an irreplaceable role. In Chinese colleges and universities, the education thought, the major setting, the curriculum system, teaching content, teaching material construction is conducted fruitful reform but due to the lag on the reform of teaching method, a direct impact on the development of teaching reform. Therefore, related innovation teaching methods, cultivate students' innovation spirit and innovation ability, is to deepen the teaching reform of colleges and universities in new period, improve quality of education, an important task of higher education implementation science development. The mechanism innovation of the higher vocational education will effectively solve the guidance to the enterprises to participate in the incentive problems of the construction of the higher vocational college, effective change due to the lack of market and enterprises to participate in the status of the higher vocational educational reform is difficult to get in-depth, and fundamentally change as a result of higher vocational educational reform because of far away from the market is like a pattern, like the water without source. Therefore, to explore the mechanism innovation of the higher vocational education and to deepen the vocational educational reform is of great significance. Build a modern teaching method system is an important task for transformation of colleges and universities personnel training mode that is of great significance and can be reflected from the listed aspects.

- It is advantageous to the development and improves students' ability in many aspects. Ability training as the main line through the use of a variety of modern teaching methods, to cultivate and improve students' thinking in images and the logical thinking ability, independent analysis and problem solving skills, professional application ability and innovation ability and related autonomous learning ability [6-7].

- To improve the teaching quality. The construction of a modern teaching method system, to the perceptual awareness of the students, and to all kinds of thinking activity of consciousness, to effectively attract the learning activities. To the internal potential and understanding of the students to mobilize the corresponding effectively.

- Promote the deepening of the reform of teaching method. To build a modern teaching method system, cannot be confined to the study of a single teaching method and practice, must be for a variety of modern teaching methods to study, research and optimize the combination, into practice. To reform the teaching methods both from the horizontal, and from the longitudinal in-depth step by step.

- To arouse students interest in learning. Using a variety of the teaching methods is helpful to arouse the enthusiasm of students' learning. As a result of the activity space, ways and means are different, different effect, colorful and can make the students know activity is very active, causing interest, to avoid the learning activities monotonous and boring.

The Practice Education. Human knowledge and the discovery of truth is this cycle after practice know, spiral process. No practice is impossible to have the innovation. Practice teaching occupies an important position in the whole teaching process, with the other teaching forms an irreplaceable role. Practice teaching refers to the close contact with theory teaching, students in the teachers' guidance is given priority to with practical operation, acquire 
knowledge and skills to improve the comprehensive quality is the combination of a series of teaching activities. Compared with the theoretical teaching, practical teaching, more investment is needed to organize the implementation of manpower material resources is not only to be constraint of experimental sites, instruments, etc. but also support from the society, the enterprise, more difficult to operate, so practical teaching is weak link of undergraduate course teaching in colleges and universities and many problems exist [8].

Since the practice teaching system to establish and implement on macro has achieved significant results that greatly improving the students' independent ability and innovation ability, these from the student's employment situation and unit of choose and employ persons every year for the feedback. Therefore, the suggestions for enhancing the teaching pattern can be listed as follows. (1) Strengthen the practice teaching base construction, enhance practical teaching effect. Practice teaching is not only need to be in classroom, but also needs in the practical teaching base and the wider world. Therefore, as an important part in practice teaching, practice teaching base construction is of great significance. To strengthen the construction of practical teaching base, for extending the space of school education, training students' practical ability, practice innovation idea has effect that cannot ignore. (2) Increase the proportion of practical courses, pay attention to practice teaching effect. School curriculum reform is to appropriately increase the proportion of practice part of school education, increase the proportion of practice, experiment and social practice and so on. (3) Set up scientific system of assessment and selection. If assessment and selection system does not pay attention to the students' practical ability and comprehensive quality of the spirit of innovation, the practical teaching is not brought to the attention of the school teachers and students, schools continue to pursue test scores ranking, nature and ignore even the sacrifice student full scale development needs. Therefore, in order to promote the all-round development of students, strengthen the practice ability, eliminate education tendency of the utilitarianism that need to establish a scientific system of assessment and selection.

Practice teaching activities are made up of several parts: as the main body of students, play leading role of teachers and role based security teaching resources and the management system, supervision and evaluation, the evaluation system is the organic combination of multiple aspects that has many aspects of knowledge, at same time, requirements subject to from a comprehensive, multidisciplinary and thinking problem for identification and judgment [9].

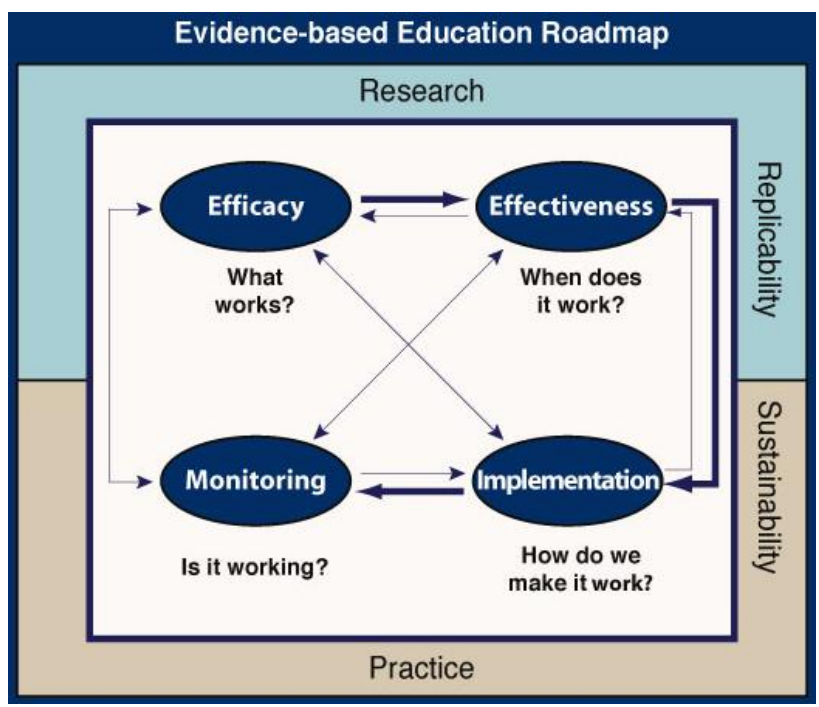

Figure 2. The Primary Components of the Practice Education

\section{The Advanced Characteristics of Internet} Plus. Internet thinking in general creative thinking, cooperative, thinking, open thinking, systematic thinking, etc., help to change the current teaching of advertising design teaching pattern backwardness, systemic between disciplines and curriculum is not strong, such problems as lack of the communication and cooperation in the teaching, to cultivate the advertisement design talents with Internet thinking. 
Accordingly, the related tips and characteristics of the Internet plus perspective can be summarized as the follows. (1) The Internet thinking highly attention to person's subjectivity. Focus on individual value, decentralization, flat organization structure is the important message that Internet thinking to people. The nature of the Internet development is to make the interaction become more efficient, both in interpersonal interaction, including human-computer interaction. (2) Internet thinking emphasizes the product thinking. Industrial age product mass production mode is replaced by the Internet age of personalized product demand. Focus on acme, quick update and crossover is an important content of the Internet age product value. (3) The spread of the Internet age based on the spread of the social and public praise and it also can be summarized as big data and the social thinking. The reputation of the foundation is to provide service value more than expected, form the gratification of spontaneous and experience which leads to base on social media since the media such as word of mouth spread quickly.

In the sense, this redefinition is for the value of individual, as a new "Renaissance". In the present, many students have formed spontaneously ecological group of Internet, the characteristics of these groups is honeycombed with independent logic and way of thinking the wisdom of the group. "Out of control" has become the norm. The speed of information transmission, students' ability of community self-organization, creating new knowledge and consensus and related influence range far beyond our imagination, students how to create a content, let cellular Internet self-organized group formation in the impulsive, thus their antipathy to the traditional way of organizing is an important content of the ideological and political education workers need to think about.

\section{Conclusion}

In this paper, we conduct research on the practice education in colleges and the universities under the background of Internet plus. In order to make the higher education teaching better adapt to the China's reform and opening up and socialist modernization construction on the talent requirements, adapt to the socialist market economic system's need for the talents training and adapt to the new trend in the development of science and technology, higher education has accelerated the pace of reform, intensify the reform of and achieved gratifying results. In macroscopic management level of higher education teaching reform, higher education workers need to good at macro thinking, foresight more need to focus on everyone's wisdom, education administrative department to grasp the global, known by the micro, decision-making is proper and the correct steps. In the future, we will conduct more in-depth analysis on the Internet plus to achieve the better performance of the college education.

\section{References}

[1] Bellamy, Jennifer L., et al. "Implementing Evidence-Based Practice Education in Social Work A Transdisciplinary Approach." Research on social work practice 23.4 (2013): 426-436.

[2] Swanson, Randel L. "Biotensegrity: A Unifying Theory of Biological Architecture With Applications to Osteopathic Practice, Education, and Research-A Review and Analysis." The Journal of the American Osteopathic Association 113.1 (2013): 34-52.

[3] Astin, Alexander W. Assessment for excellence: The philosophy and practice of assessment and evaluation in higher education. Rowman \& Littlefield Publishers, 2012. 
[4] Doswell, Willa Marlene, et al. "mHealth: Technology for nursing practice, education, and research." Journal of Nursing Education and Practice 3.10 (2013): p99.

[5] Olsen, Nina R., et al. "Evidence based practice in clinical physiotherapy education: a qualitative interpretive description." BMC medical education 13.1 (2013): 52.

[6] De Grez, Luc, Martin Valcke, and Irene Roozen. "The differential impact of observational learning and practice-based learning on the development of oral presentation skills in higher education." Higher Education Research \& Development 33.2 (2014): 256-271.
[7] Stylianides, Andreas J., and Gabriel J. Stylianides. "Seeking research-grounded solutions to problems of practice: classroom-based interventions in mathematics education." ZDM 45.3 (2013): 333-341.

[8] Urban, Mathias, et al. "Towards competent systems in Early Childhood Education and Care. Implications for policy and practice." European Journal of Education 47.4 (2012): 508-526.

[9] Morton, Janne. "Communities of practice in higher education: A challenge from the discipline of architecture." Linguistics and Education 23.1 (2012): 100-111. 